\title{
ANÁLISE DO RESULTADO DAS OPERAÇÕES DE SEGUROS NAS EMPRESAS DO SETOR DE VAREJO
}

\author{
Fabiana Lopes da Silva ${ }^{1}$ \\ Betty Lilian Chan ${ }^{2}$
}

\section{RESUMO $^{12}$}

No setor de varejo, a distribuição de seguros no canal de afinidades tem crescido ao longo do tempo no mercado brasileiro. Assim, o presente artigo tem por objetivo realizar uma análise exploratória sobre a importância do segmento de seguros para o setor de varejo, bem como levantar as suas principais características. Para tanto, foram analisadas as demonstrações contábeis de 7 empresas que atuam no setor de varejo, nos anos de 2015 e 2016. Os resultados sugerem importância crescente das receitas obtidas nos segmentos financeiros, de seguros e cartões em relação ao faturamento das vendas no varejo. Além disso, os resultados operacionais com as operações financeiras e de seguros de algumas empresas foram superiores aos resultados obtidos no setor de varejo.

Palavras-chave: Seguro afinidade; Setor de varejo.

1 Professora do Departamento de Atuária e Métodos Quantitativos da PUC-SP e do Mestrado Profissional em Controladoria e Finanças da Faculdade FIPECAFI.

2 Professora do Programa de Mestrado da FECAP. 
-• Economia Brasileira em Debate

\section{INTRODUÇÃO}

O setor de varejo tem explorado uma importante fonte de alternativa de receita: o segmento financeiro e de seguros.

O seguro é um instrumento criado pelo homem para amenizar adversidades inesperadas, sendo baseado no conceito de mutualismo.

A distribuição de seguros no canal afinidades, também conhecido como affinity, tem crescido ao longo do tempo no mercado brasileiro. Esse canal se caracteriza pela venda de seguros por intermédio de parceiros comerciais, os quais costumam ser empresas de varejo, financeiras, cartôes de crédito, associações ou empresas de serviços de utilidade (energia elétrica, gás, telefone etc.).

Os seguros comercializados no segmento afinidades tendem a ser distribuídos de forma simples e massificada, cabendo destacar os seguintes produtos: seguro prestamista; garantia estendida; roubo, furto ou quebra acidental de celulares; residencial; acidentes pessoais; etc.

Esse modelo de negócio acaba fortalecendo o relacionamento do canal varejista com seus clientes, agregando novos produtos à sua marca. Além disso, como esses seguros, normalmente, são de baixo custo e diluído em parcelas, tem uma forte expressão entre as classes $\mathrm{C}$ e $\mathrm{D}$, destacando-se o seu papel social.

Para o varejista, são produtos que não ocupam espaços físicos na loja e podem representar importante fonte de receita com baixo investimento, seja por conta de recebimento de front fee para exploração do seu canal de venda, ou pelas comissões/pró-labore na venda de seguros ou por participação nos lucros dessas operações.

Ademais, para se ter uma ideia, no mercado brasileiro, conforme dados divulgados na Superintendência de Seguros Privados (Susep), o prêmio direto de garantia estendida, seguro que, em geral, oferece um a dois anos adicionais de proteção ao produto em relação ao prazo da garantia do fabricante, em 2007 foi de, aproximadamente, R \$ 1,18 bilhões, enquanto em 2016 foi de $\mathrm{R}$ \$ 2,58 bilhões, o que representa um crescimento de $119 \%$.

Já, no seguro prestamista, modalidade de seguro que busca conferir alguma proteção financeira para as pessoas que têm prestações a serem pagas, sejam ela decorrentes de empréstimos, financiamentos ou alguma outra dívida, o prêmio direto era de cerca de R \$ 2,07 bilhões em 2007 e R \$ 7,70 bilhões em 2016, indicando um crescimento em termos nominais na ordem de 272\% (Susep). 
A relevância desses números mostra a importância econômica do objeto do presente estudo. Nesse sentido, tendo-se em vista a carência de pesquisas acadêmicas relativas a seguros, mais especificamente, ao segmento de afinidades, o presente artigo tem por objetivo realizar uma análise exploratória sobre a importância do segmento de seguros para o setor de varejo, bem como levantar as suas principais características.

\section{SETOR DE VAREJO}

Segundo Kotler (1998), o varejo inclui todas as atividades relativas à venda de produtos ou serviços diretamente ao consumidor final, para o uso pessoal e não comercial. Nesse caso, um varejista ou uma loja de varejo é qualquer empreendimento comercial cujo faturamento decorre da venda de pequenos lotes no varejo (KOTLER, 1998).

O momento vivenciado no país, de forte retração econômica, tem afetado o ânimo dos consumidores e adiado os planos de investimentos das empresas, o que traz diversas consequências a inúmeros setores da economia, dentre eles o de varejo e bens de consumo (PwC BRASIL, 2016).

O Gráfico 1 a seguir apresenta o Índice de Confiança do Consumidor elaborado pela FGV/IBRE, que é "uma pesquisa mensal que procura captar o sentimento do consumidor em relação ao estado geral da economia e de suas finanças pessoais. Quando o consumidor está satisfeito, e otimista em relação ao futuro, tende a gastar mais; quando está insatisfeito, pessimista, gasta menos".

Gráfico 1 Índice de Confiança do Consumidor (dessazonalizado).

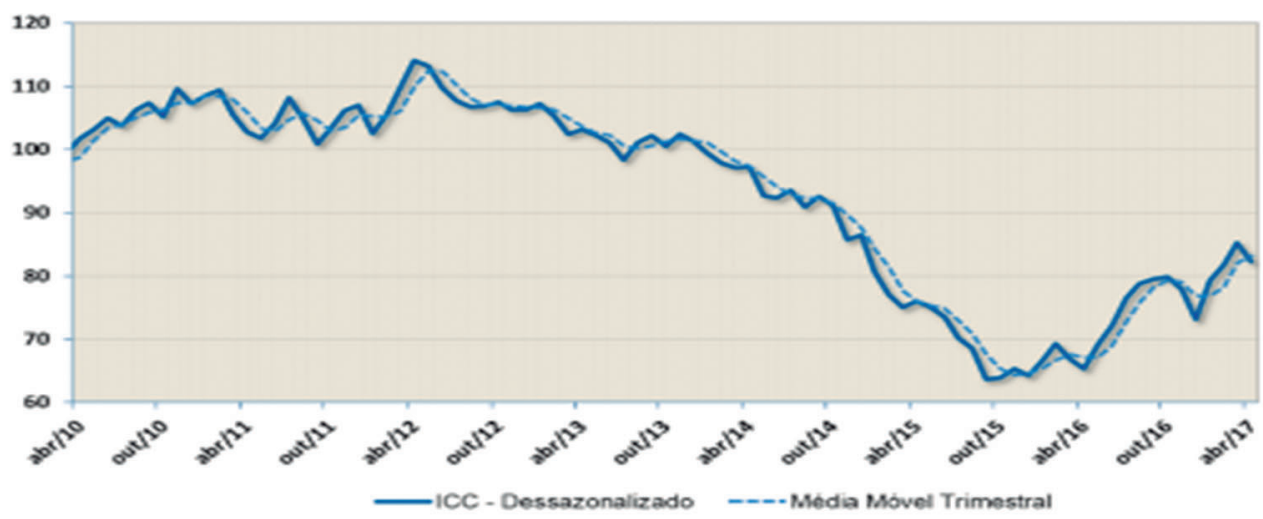

Fonte: FGV/IBRE. 
De acordo com a FGV “a confiança do consumidor, portanto, atua como fator redutor ou indutor do crescimento econômico. O monitoramento do sentimento do consumidor tem o objetivo de produzir sinalizações de suas decisões de gastos e poupança futuras, constituindo indicadores úteis na antecipação dos rumos da economia no curto prazo". Observa-se pelo Gráfico 1 que houve uma melhora no ânimo dos consumidores, o que refletiu no aumento do índice de confiança sobre as intenções de compra de bens nos próximos meses de 2017.

De acordo com matéria publicada pela Exame (2017), o desempenho ruim do setor de varejo em 2016 foi "consequência de uma série de fatores: a alta inflação, que corroeu o poder de compra e a confiança dos consumidores nos primeiros meses do ano, o desemprego e o crédito mais caro e escasso".

Segundo dados da Sociedade Brasileira de Varejo e Consumo (SBVC) o consumo das famílias em 2015 foi de R 2.8 trilhões, sendo que "o consumo das famílias é a principal referência do volume que o varejo como um todo movimenta no país" (SBVC, 2017). Em termos de PIB, o consumo representa 47,5\% do PIB. Se considerar apenas o varejo restrito (varejo de bens de consumo exceto carros e construção) "representou 23,62\% de impacto no PIB com um volume de R \$ 1,4 trilhões" (SBVC, 2017).

O Gráfico 2 apresenta o índice acumulado de vendas para móveis e eletrodomésticos, o qual observa-se uma redução significativa nos anos de 2014 e 2015.

Gráfico 2 Índice Acumulado de vendas (12 meses) - Móveis e eletrodomésticos.

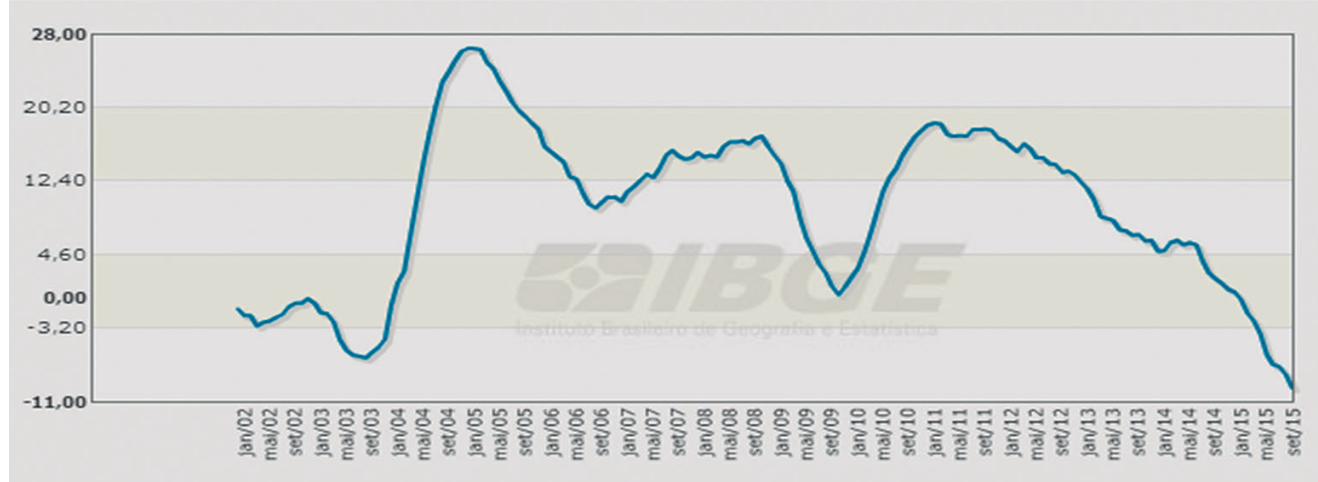

Fonte: IBGE, Pesquisa Mensal do Comércio 2000/jan-2015/set. 
Análise do resultado das operações de seguros nas empresas do setor de varejo ••

O Gráfico 3 apresenta as vendas de tecidos, vestuário e calçados, na qual observa-se a tendência de queda nas vendas entre 2013 e 2014.

Gráfico 3 Índice Acumulado de vendas (12 meses) - Tecidos, vestuário e calçados.

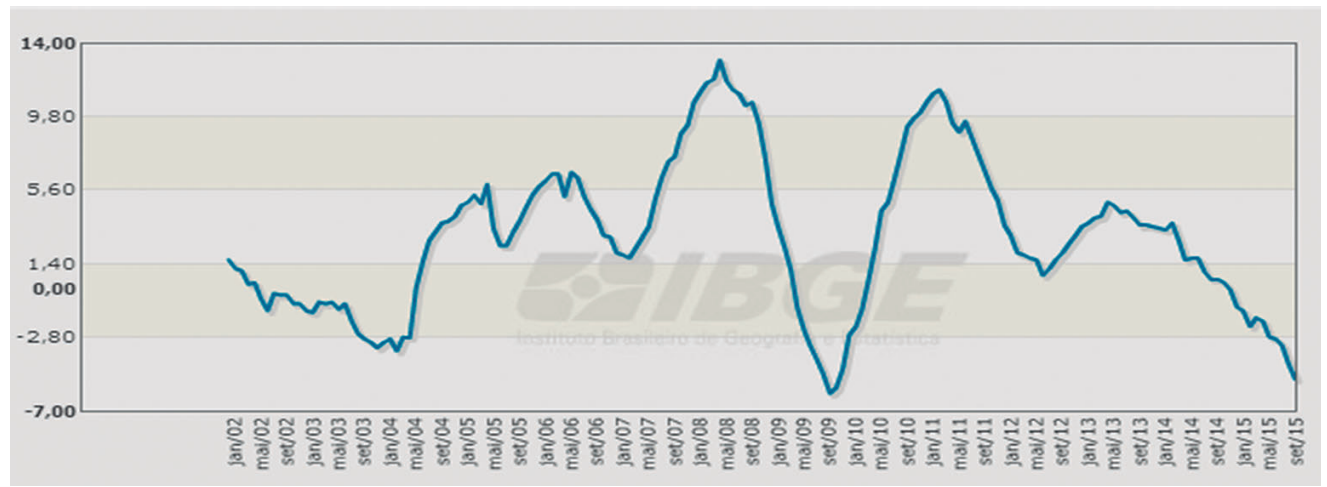

Fonte: IBGE, Pesquisa Mensal do Comércio 2000/jan. 2015/set.

O Gráfico 4 apresenta a pesquisa trimestral de intenção de compra no varejo referente ao $4^{\circ}$ Trimestre de 2016 (outubro - dezembro) elaborado pelo IBEVAR e o PROVAR - FIA, entidade conveniada à FEA-USP. O propósito desta pesquisa é sinalizar para varejistas a intenção de compra e de gasto dos consumidores para o próximo trimestre e investigar as expectativas com relação à compra das seguintes categorias de produtos: linha branca; móveis; eletroeletrônicos; material de construção; informática; cine e foto; telefonia e celulares; cama, mesa e banho; eletro portáteis; automóveis e motos; e imóveis.

Gráfico 4 Intenção de Compra (4T/2013 a 4T/2016).

Intenção de compra

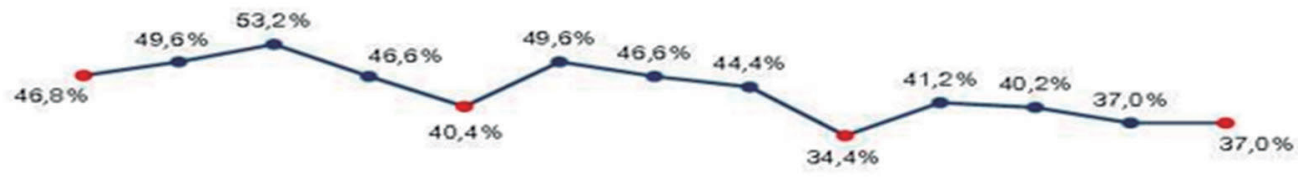

$\begin{array}{lllllllllll}4 \mathrm{~T} 13 & 1 \mathrm{~T} 14 & 2 \mathrm{~T} 14 & 3 \mathrm{~T} 14 & 4 \mathrm{~T} 14 & 1 \mathrm{~T} 15 & 2 \mathrm{~T} 15 & 3 \mathrm{~T} 15 & 4 \mathrm{~T} 15 & 1 \mathrm{~T} 16 & \text { 2T16 }\end{array}$

Fonte: PROVAR.

Observa-se pelo Gráfico 4, uma redução expressiva na intenção de compra dos consumidores para o próximo trimestre. 
-• Economia Brasileira em Debate

Gráfico 5 Intenção de Compra por categoria (dez. 2016).

\section{Intenção de compras por categoria de produto}

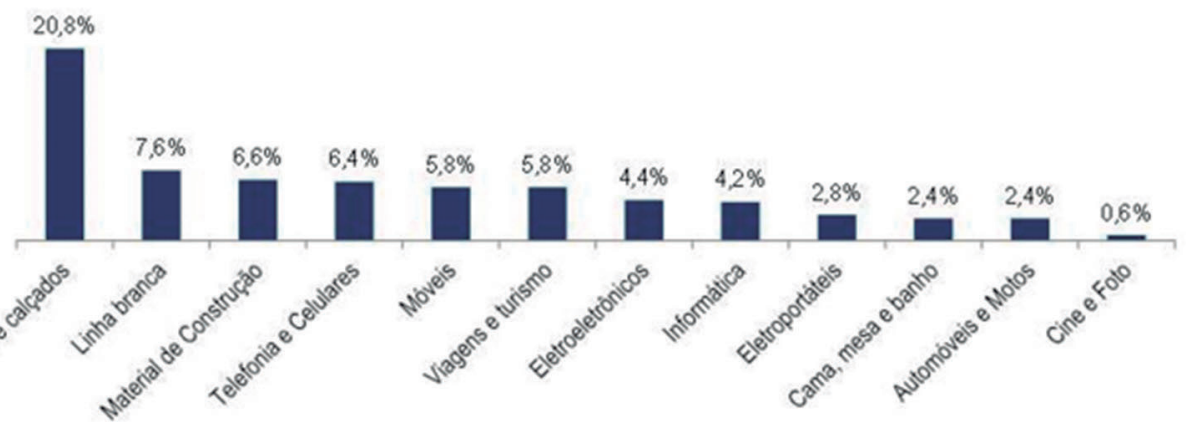

Fonte: PROVAR.

Já o Gráfico 5, apresenta a intenção de compra por categoria de produto, destacando-se o segmento de vestuário e calçados, linha branca, material de construção, telefonia celular, dentre outros.

Gráfico 6 Intenção de compra no varejo série histórica.

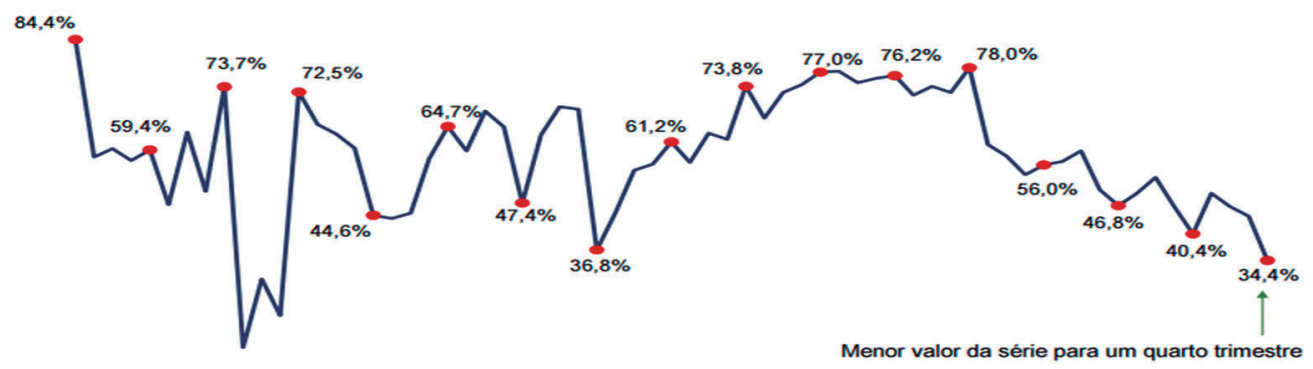

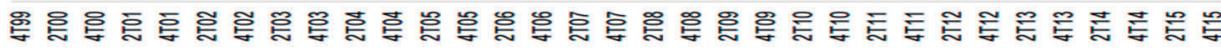
Fonte: PROVAR.

Ao observar, a evolução histórica do índice de intenção de compra, observa-se que o ano de 2015 apresentou o menor valor da série, quando analisada entre o $4{ }^{\circ}$. Trimestre de 1999 a $4^{\circ}$. Trimestre de 2015.

\section{MERCADO DE SEGURO AFINIDADES}

O mercado segurador brasileiro tem apresentado forte crescimento nos últimos, impulsionado, principalmente, pela estabilização da economia e aumento no consumo (CHAN, 2010). 
De acordo com Souza (2006, p. 14) a estabilidade econômica fez com que a população brasileira deixasse de se preocupar com os reajustes diários de preços e passasse a pensar mais no futuro. A mudança de comportamento foi um impulso para a expansão do setor de seguros, previdência e capitalização (SILVA e CHAN, 2015).

Essa evolução, pode ser constata pela 1 que apresenta os valores arrecadados com prêmios diretos no mercado de seguros no Brasil, entre 2001 a 2014, bem como os respectivos percentuais de participação no PIB.

Tabela 1 Evolução dos Prêmios Diretos de Seguros e Participação no PIB (\%).

\begin{tabular}{|c|c|c|}
\hline Ano & $\begin{array}{c}\text { Prêmios diretos } \\
\text { (valores em R\$ mil) }\end{array}$ & Participação no PIB (\%) \\
\hline 2001 & $24.211 .622,00$ & $1,86 \%$ \\
\hline 2002 & $23.910 .777,00$ & $1,62 \%$ \\
\hline 2003 & $30.717 .421,00$ & $1,81 \%$ \\
\hline 2004 & $37.546 .345,00$ & $1,93 \%$ \\
\hline 2005 & $42.561 .865,00$ & $1,98 \%$ \\
\hline 2006 & $49.587 .528,00$ & $2,09 \%$ \\
\hline 2007 & $58.443 .093,00$ & $2,20 \%$ \\
\hline 2008 & $67.816 .374,00$ & $2,24 \%$ \\
\hline 2009 & $76.611 .206,00$ & $2,36 \%$ \\
\hline 2010 & $90.088 .893,00$ & $2,39 \%$ \\
\hline 2011 & $105.031 .660,00$ & $2,54 \%$ \\
\hline 2012 & $129.340 .524,00$ & $2,94 \%$ \\
\hline 2013 & $145.348 .303,00$ & $3,00 \%$ \\
\hline 2014 & $164.360 .612,00$ & $3,21 \%$ \\
\hline
\end{tabular}

Fonte: Susep (2014).

Conforme Tabela 1, observa-se que o mercado segurador apresentou significativa expansão nos últimos anos, passando de aproximadamente $\mathrm{R}$ \$ 24 bilhões de prêmios diretos em 2001 para $\mathrm{R} \$ 164$ bilhões, demonstrando um crescimento de cerca de $583 \%$ no período em análise.

A venda de seguros no varejo é caracterizada por se tratar de uma distribuição em massa, por intermédio de um modelo de negócio B2B2C (business to business to 
consumer), diferentemente da comercialização de seguros tradicionais, conhecidos por ser B2C (business to consumer).

Nesse caso, o varejista passa a promover a venda de seguros em nome da seguradora e, portanto, só estará autorizado para exercer esse papel caso se torne oficialmente um representante de seguros. Para tanto, é necessário estabelecer um contrato com a sociedade seguradora que pretende representar antes do início das operações.

De acordo com o manual da CNSeg, é obrigação do representante de seguros e da seguradora basear-se nas seguintes diretrizes:

- É obrigatório oferecer serviços de qualidade.

- É obrigatório disponibilizar informações completas e de forma transparente.

- O seguro é opcional.

- É proibido condicionar desconto no preço do produto para a contratação do seguro.

- É proibido condicionar desconto no preço do seguro para a compra do produto.

- É obrigatória a aceitação expressa pelo consumidor.

- É obrigatório a disponibilização do extrato do contrato.

- Prazo de vigência.

- O consumidor tem o direito de se arrepender.

- É proibida a renovação automática.

- $\mathrm{O}$ endosso do seguro deve ser comunicado à seguradora.

Cabe destacar que a venda casada de seguro é proibida, sob pena de multa a ser aplicada pela Susep.

$\mathrm{Na}$ comercialização de seguros no canal varejista, existem 3 possíveis documentos para a formalização do contrato de seguros, a saber:

- Apólice Individual: é o documento que, após o preenchimento e a assinatura da proposta, formaliza a aceitação do segurado para as coberturas contratadas. A seguradora tem o prazo de 15 dias a contar da data de adesão para aceitar ou recusar o seguro.

- Bilhete de Seguro: é o documento que formaliza a aceitação imediata do segurado para as coberturas contratadas e que dispensa o preenchimento 
de proposta de aprovação. Ele deve ser entregue ao segurado no ato da contratação.

- Certificado de seguro: é o documento que contém todas as condições de funcionamento do seguro, estabelecendo as obrigações e os direitos do consumidor e da seguradora. (CNSeg).

Nos referidos documentos, devem constar as informações essenciais para a compreensão do seguro, como as coberturas, as exclusões, os valores de indenização, os contatos da seguradora, o período de vigência do seguro etc. Caberá também ao varejista disponibilizar as Condiçōes Gerais do seguro.

Além disso, vale ressaltar que na desistência da contratação de seguros em até 7 dias corridos a contar da venda do seguro, será devolvido o valor integral do prêmio pago até então.

Para a empresa varejista, a comercialização de seguros representa importante fonte de receita, com baixo investimento, além de ser vista como uma forma de fidelização de clientes e valorização da marca por representar benefícios adicionais aos seus clientes.

Para a exploração do seu canal de vendas, a rede varejista pode ou não receber um front fee da seguradora, dependendo do potencial que esta entende que a rede pode representar para a comercialização de seus produtos. Para se ter uma ideia da magnitude desses números, segue alguns exemplos divulgados na mídia:

- $\quad$ Em mar/2017, Lojas Marisa - firmou contrato com a Assurant para venda de seguros e assistência. O contrato tem prazo de cinco anos e a varejista receberá $\mathrm{R} \$ 75$ milhões, à título de antecipação, em duas parcelas, uma em março e outra em junho de 2017 (VALOR ECONÔMICO, 29.03.2017).

- $\quad$ Em dez./2016, foi divulgado que a Zurich pagará $\mathrm{R} \$ 270$ milhões para vender seguros na Via Varejo durante 6 anos, sendo o volume de negócios estimados em $\mathrm{R} \$ 3$ bilhões. Os seguros a serem comercializados são roubo, furto e quebra acidental de celulares, seguro prestamista, seguro de acidentes pessoais e seguro residencial (SONHO SEGURO, 21.12.2016)

- Seguradora AXA fechou contrato com Pernambucanas de R 2 bilhões em prêmios - duração de 10 anos (16/09/2016) - para explorar todo o canal - exclusividade na venda de seguros (VALOR ECONÔMICO, 16.09.2016). 
- A Magazine Luiza informou em 2015 que renovou acordo de aliança com o BNP Paribas Cardif com extensão dos direitos e obrigações previstos nos acordos entre Magazine Luiza e Cardif e entre Magazine Luiza e Luizaseg por mais dez anos e receberá $\mathrm{R} \$ 330$ milhões de reais (EXAME, 2015).

Tabela 2 Percentual da Despesa de Comercialização no Segmento de Garantia Estendida das Seguradoras que tiveram mais de R\$100 milhões de Prêmios Diretos em 2016.

\begin{tabular}{|l|c|c|c|c|}
\hline \multicolumn{1}{|c|}{ Empresa } & \multicolumn{1}{|c|}{$\begin{array}{c}\text { Prêmio } \\
\text { direto }\end{array}$} & $\begin{array}{c}\text { Prêmio } \\
\text { ganho }\end{array}$ & $\begin{array}{c}\text { Despesa } \\
\text { comercial }\end{array}$ & $\begin{array}{c}\text { \% Despesas de } \\
\text { comercialização }\end{array}$ \\
\hline $\begin{array}{l}\text { Zurich Minas Brasil } \\
\text { Seguros S.A. }\end{array}$ & 1.058 .148 .072 & 645.402 .714 & 419.775 .313 & $65 \%$ \\
\hline $\begin{array}{l}\text { Cardif do Brasil Seguros e } \\
\text { Garantias S.A. }\end{array}$ & 378.895 .138 & 155.596 .689 & 107.833 .669 & $69 \%$ \\
\hline Luizaseg Seguros S.A. & 375.039 .230 & 378.813 .566 & 261.241 .780 & $69 \%$ \\
\hline $\begin{array}{l}\text { Virginia Surety Companhia } \\
\text { de Seguros do Brasil }\end{array}$ & 241.024 .654 & 213.682 .415 & 135.247 .763 & $63 \%$ \\
\hline Assurant Seguradora S.A. & 219.834 .309 & 230.829 .077 & 135.436 .012 & $59 \%$ \\
\hline Itau Seguros S.A. & 112.556 .312 & 790.510 .295 & 504.725 .619 & $64 \%$ \\
\hline Mapfre Seguros Gerais S.A. & 103.401 .389 & 118.020 .125 & 68.820 .421 & $58 \%$ \\
\hline
\end{tabular}

Fonte: Susep.

Além de possível pagamento de front fee, as seguradoras costumam pagar comissões/pró-labore significativas pela venda do seguro e participações nos lucros dessas operações. A tabela a seguir mostra o percentual da despesa de comercialização no segmento de garantia estendida em 2016 para as seguradoras que tiveram mais de R \$ 100 milhões de prêmios diretos nesse ano.

Em 2016, o percentual de despesa de comercialização do setor foi de 68\% para garantia estendida. Esses números mostram a relevância do setor de seguros no canal de afinidades, onde se encontra o mercado varejista.

\section{PRINCIPAIS MODALIDADES DE SEGUROS AFINIDADES}

Dentre as principais modalidades de seguros ofertados no canal de varejo, pode-se destacar: seguro prestamista, garantia estendida, seguro de proteção financeira, seguro de acidentes pessoais, seguro contra roubo, furto e quebra acidental de celulares e notebooks. 
O seguro prestamista garante proteção financeira para as pessoas que têm prestaçôes a serem pagas, sejam ela decorrentes de empréstimos, financiamentos ou alguma outra dívida (SILVA e CHAN, 2015).

Tendo-se em vista que a situação financeira de um indivíduo pode ser comprometida em função da perda involuntária do emprego ou incapacidade, temporária ou não, levando-o a dificuldades para honrar o pagamento dos seus compromissos, essa modalidade tem-se destacado nos últimos anos (SILVA e CHAN, 2015). Em 2007 o prêmio direto era de cerca de R\$2,07 bilhôes em 2007 e, em 2016 encerrou o ano com $\mathrm{R} \$ 7,70$ bilhōes, indicando um crescimento em termos nominais na ordem de $272 \%$ (SUSEP).

O seguro prestamista faz parte do ramo de seguro de pessoas. Segundo Guia de Orientação e Defesa do Segurado elaborado pela Susep (2006, p. 33), “o seguro de pessoas tem por objetivo garantir o pagamento de uma indenização ao segurado e aos seus beneficiários, observadas as condições contratuais e as garantias contratadas".

São exemplos de seguros de pessoas, o seguro de vida, seguro funeral, seguro de acidentes pessoais, seguro educacional, seguro viagem, seguro de diária de internação hospitalar, seguro perda de renda, seguro de diária de incapacidade temporária e o seguro prestamista (SILVA e CHAN, 2015).

De acordo com a Susep, o seguro de Garantia Estendida tem como objetivo "fornecer ao segurado, facultativamente e mediante o pagamento de prêmio, a extensão temporal da garantia do fornecedor de um bem adquirido e, quando prevista, sua complementação".

Quanto às coberturas, os planos de seguro de Garantia Estendida devem, obrigatoriamente, oferecer uma das seguintes coberturas básicas (SUSEP, 2017):

a. Extensão de garantia original: contrato cuja vigência inicia-se após o término da garantia do fornecedor e que contempla as mesmas coberturas e exclusões oferecidas pela garantia do fornecedor.

b. Extensão de garantia original ampliada: contrato cuja vigência inicia-se após o término da garantia do fornecedor e que contempla as mesmas coberturas oferecidas pela garantia do fornecedor, apresentando, adicionalmente, a inclusão de novas coberturas, desde que não enquadradas em outros ramos específicos de seguro.

c. Extensão de garantia reduzida: contrato cuja vigência inicia-se após o término da garantia do fornecedor e que pode contemplar coberturas reduzidas comparativamente àquelas oferecidas pela garantia do fornecedor. Esta modalidade aplica-se somente a veículos automotores e a bens que possuem apenas garantia legal. 
Além disso, de maneira facultativa, "os planos de seguro de Garantia Estendida poderão oferecer a cobertura de Complementação de Garantia, cuja vigência inicia-se simultaneamente com a garantia do fornecedor, contemplando coberturas não previstas ou excluídas pela garantia do fornecedor e desde que não enquadradas em outros ramos específicos de seguro" (SUSEP, 2017).

Modalidade de seguro para a cobertura de equipamentos eletrônicos, tais como celulares, smartphone, notebooks, tablets, entre outros, que visa garantir o reparo ou reposição do bem em caso de roubo, furto qualificado ou quebra acidental.

\section{INFORMAÇÕES POR SEGMENTO (PRONUNCIAMENTO TÉCNICO CPC 22)}

A globalização e a presença de investidores internacionais intensificaram a necessidade de transparência das demonstrações contábeis e que represente de maneira fidedigna a realidade econômica das empresas (BOSCOV, 2009).

Assim, a fim de adequar à Lei das Sociedades por Ações (Lei n. 6404/76) às novas necessidades locais e globais de informação foi promulgada a Lei 11.638/2007, que trouxe mudanças significativas na contabilidade brasileira, principalmente, permitindo a adoção de padrões contábeis internacionais (IFRS) (FIPECAFI e ERNST \& YOUNG, 2010).

Dentre tais mudanças, tem-se a incorporação de uma nova prática de divulgação de resultados que exige a evidenciação de informações por segmentos, pela International Financial Reporting Standard (IFRS) 8, que corresponde ao CPC 22 (Informações por Segmento).

O CPC 22 menciona que a entidade deve "divulgar informações que permitam aos usuários das demonstrações contábeis avaliarem a natureza e os efeitos financeiros das atividades de negócio nos quais está envolvida e os ambientes econômicos em que opera”.

De acordo com Boscov (2009, p. 55), a evidenciação de informações por segmento contribui "para melhorar a capacidade dos usuários de informações contábeis em analisar as ações e reações da gerência, fazer previsões e conhecer os riscos e oportunidades dos diversos negócios". Ou seja, possibilita que os usuários das informações possam conhecer a forma como a administração da empresa gerencia suas atividades (MAPURANGA, PONTE e HOLANDA, 2014). 
Na visão de Mourad apud Pinheiro e Boscov (2015), "as informações por segmento auxiliam no entendimento do negócio como um todo e ganham caráter estratégico e suscetível a erros, o que torna as empresas cautelosas ao divulgarem as informações para não causarem impactos negativos".

O CPC 22 afirma que um segmento operacional é um componente de entidade:

(a) que desenvolve atividades de negócio das quais pode obter receitas e incorrer em despesas (incluindo receitas e despesas relacionadas com transaçôes com outros componentes da mesma entidade).

(b) cujos resultados operacionais são regularmente revistos pelo principal gestor das operaçōes da entidade para a tomada de decisões sobre recursos a serem alocados ao segmento e para a avaliação do seu desempenho; e

(c) para o qual haja informação financeira individualizada disponível.

Cabe destacar que não é necessário que todos os segmentos sejam divulgados, mas apenas aqueles que foram mais representativos. Nesse sentido, o CPC 22 apresenta dois parâmetros mínimos quantitativos, os de $10 \%$ e o de $75 \%$, conforme destacado a seguir:

13. A entidade deve divulgar separadamente as informaçôes sobre o segmento operacional que atenda a qualquer um dos seguintes parâmetros:

(a) sua receita reconhecida, incluindo tanto as vendas para clientes externos quanto as vendas ou transferências intersegmentos, é igual ou superior a $10 \%$ da receita combinada, interna e externa, de todos os segmentos operacionais.

(b) o montante em termos absolutos do lucro ou prejuízo apurado é igual ou superior a $10 \%$ do maior, em termos absolutos, dos seguintes montantes:

(i) lucro apurado combinado de todos os segmentos operacionais que não apresentaram prejuízos; e

(ii) prejuízo apurado combinado de todos os segmentos operacionais que apresentaram prejuízos.

(c) seus ativos são iguais ou superiores a $10 \%$ dos ativos combinados de todos os segmentos operacionais.

Além disso, a companhia poderá divulgar segmentos operacionais que não atinjam quaisquer dos parâmetros mínimos quantitativos e podem ser apresentados separadamente se a administração entender que essa informação sobre o segmento possa ser útil para os usuários das demonstrações contábeis (CPC 22).

Assim, o entendimento da nota explicativa sobre informações por segmento será fundamental para o presente estudo, fornecendo os elementos necessários para a avaliação da representatividade dos segmentos operacionais nos negócios. 
-• Economia Brasileira em Debate

\section{METODOLOGIA}

A tipologia de pesquisa adotada se baseia, predominantemente, em uma abordagem empírico-analítica, por meio de uma análise exploratória sobre a importância do segmento de seguros para o setor de varejo.

Assim, foram levantadas as demonstrações contábeis dos exercícios sociais findos em 31.12.2016 e 31.12.2015, a fim de verificar a contribuição do segmento financeiro e de seguros para o resultado da companhia.

Foram selecionados os seguintes setores que estão disponíveis no site da BM\&FBovespa, para a seleção das empresas de capital aberto:

- Comércio de eletrodomésticos.

- Produtos diversos.

- Tecido, vestuário e calçados.

- Comércio e distribuição de alimentos.

A partir dos setores selecionados, foram levantadas as demonstraçóes contábeis das seguintes empresas:

- Arezzo Indústria e Comércio S.A.

- B2W - Companhia Digital S.A.

- $\quad$ BR Home Centers.

- Companhia Brasileira de Distribuição S.A.

- Drufry.

- $\quad$ Grazziotin S.A.

- Guararapes Confecções S.A. (Lojas Riachuelo).

- Hypermarcas S.A.

- $\quad$ IBG Eletrônica S.A.

- Lojas Americanas S.A.

- Lojas Hering S.A.

- Lojas Marisa S.A.

- Lojas Renner S.A.

- Magazine Luiza S.A.

- Restoque Comércio e Confecções de Roupas S.A. (Le Lis Blanc)

- Saraiva S.A. Livreiros Editores. 
Análise do resultado das operações de seguros nas empresas do setor de varejo $\quad$ ••

- Via Varejo S.A.

- Whirlpool S.A.

Além disso, também foram analisadas as demonstrações financeiras das Casas Pernambucanas (Arthur Lundgren Tecidos S.A.), que mesmo não sendo companhia de capital aberto, foi selecionada tendo em vista suas operações no setor de cartôes e de seguros.

Após o levantamento das demonstrações contábeis das empresas selecionadas foram analisadas as notas explicativas e Relatório da Administração a fim de levantar informações se a empresa atua no setor de varejo, se tem produtos financeiros e de seguros, bem como se tais informações estão disponíveis e segregadas.

Tabela 3 Receita Bruta do Segmento Varejo (em Milhões de R\$) - 2015 e 2016.

\begin{tabular}{|l|c|c|c|}
\hline \multicolumn{1}{|c|}{ Empresas selecionadas } & $\mathbf{2 0 1 6}$ & $\mathbf{2 0 1 5}$ & \% Crescimento de vendas \\
\hline Magazine Luiza & 11.324 & 10.455 & $8,30 \%$ \\
\hline Via Varejo & 20.055 & 20.046 & $0,04 \%$ \\
\hline Companhia Brasileira de Distribuição & 45.267 & 40.519 & $11,72 \%$ \\
\hline Casas Pernambucanas & 3.720 & 4388 & $-15,22 \%$ \\
\hline Lojas Marisa & 2.224 & 2482 & $-10,39 \%$ \\
\hline Lojas Renner & 5.721 & 5.451 & $4,95 \%$ \\
\hline Lojas Riachuelo & 4.266 & 4.073 & $4,74 \%$ \\
\hline Média & $\mathbf{1 3 . 2 2 5}$ & $\mathbf{1 2 . 4 8 8}$ & $\mathbf{0 , 5 9 \%}$ \\
\hline
\end{tabular}

Fonte: Elaborado pelas autoras.

Especificamente, buscou-se tais informações nas notas explicativas que tratam de informações por segmento (CPC 22) e no detalhamento das receitas e despesas da companhia. Vale destacar que algumas empresas não apresentaram informações sobre a atuação no segmento financeiro e de seguros, que permitisse uma análise mais apurada de tais operações. Nesse caso, foram excluídas 12 empresas para a composição da amostra final.

Assim, empresas que apresentaram informações sobre o segmento financeiro e de seguros, totalizando 7 empresas, que são apresentadas na Tabela 3.

Observa-se, pela Tabela 3 que as empresas analisadas tiveram em 2016 receita bruta média de R\$ 13.225 milhões, apontando um crescimento médio de 0,59\% no período analisado. 
-• Economia Brasileira em Debate

O tópico a seguir apresenta os resultados e as análises efetuadas a partir das demonstrações contábeis das empresas selecionadas.

\section{ANÁLISE DOS RESULTADOS}

A Tabela 4 apresenta a receita bruta obtida pelas empresas no ano de 2016, destacando-se as receitas obtidas nos segmentos financeiro e de seguros.

Com base na Tabela 4 é possível verificar a representatividade dos segmentos de seguros e financeiro (crédito pessoal, cartões, entre outros) em relação ao faturamento do segmento de varejo.

Em termos percentuais médios, verifica-se que o segmento financeiro representou na média $11,76 \%$ das receitas obtidas no segmento de varejo pelas empresas (Magazine Luiza, Via Varejo, Casas Pernambucanas e Lojas Marisa) em 2016. No caso das Casas Pernambucanas, esse percentual atingiu aproximadamente $26 \%$ da receita com o varejo.

Tabela 4 Receitas do Varejo, Operações Financeiras e de Seguros (Milhões de R\$ e \%) 2016.

\begin{tabular}{|c|c|c|c|c|c|c|c|}
\hline \multirow[b]{2}{*}{ Empresas } & \multirow{2}{*}{$\begin{array}{c}\begin{array}{c}\text { Receita } \\
\text { bruta do } \\
\text { varejo }\end{array} \\
\text { RS } \\
\text { milhões }\end{array}$} & \multicolumn{2}{|c|}{$\begin{array}{c}\text { Receita } \\
\text { das operações } \\
\text { financeiras }\end{array}$} & \multicolumn{2}{|c|}{$\begin{array}{c}\text { Receita } \\
\text { das operações de } \\
\text { seguros }\end{array}$} & \multicolumn{2}{|c|}{$\begin{array}{c}\text { Receita } \\
\text { com cartões, } \\
\text { seguros e produtos } \\
\text { financeiros }\end{array}$} \\
\hline & & $\begin{array}{c}\text { R\$ } \\
\text { milhões }\end{array}$ & $\begin{array}{l}0 \% \text { da } \\
\text { receita } \\
\text { bruta }\end{array}$ & $\begin{array}{c}\text { RS } \\
\text { milhões }\end{array}$ & $\begin{array}{l}0 \% \text { da } \\
\text { receita } \\
\text { bruta }\end{array}$ & $\begin{array}{c}\text { RS } \\
\text { milhões }\end{array}$ & $\begin{array}{l}\% \% \text { da } \\
\text { receita } \\
\text { bruta }\end{array}$ \\
\hline Magazine Luiza & 11.324 & 835 & $7,37 \%$ & 182 & $1,61 \%$ & & \\
\hline Via Varejo & 20.055 & 1.421 & $7,09 \%$ & 1.455 & $7,26 \%$ & & \\
\hline $\begin{array}{l}\text { Companhia } \\
\text { Brasileira de } \\
\text { Distribuição }\end{array}$ & 45.267 & & & 294 & $0,65 \%$ & & \\
\hline $\begin{array}{l}\text { Casas } \\
\text { Pernambucanas }\end{array}$ & 3.720 & 979 & $26,32 \%$ & 97 & $2,61 \%$ & & \\
\hline Lojas Marisa & 2.224 & 139 & $6,25 \%$ & & & 490 & $22,03 \%$ \\
\hline Lojas Renner & 5.721 & & & & & 730 & $12,76 \%$ \\
\hline Lojas Riachuelo & 4.266 & & & & & 1.601 & $37,53 \%$ \\
\hline Média & 13.225 & 843 & $11,76 \%$ & 507 & $3,03 \%$ & 940 & $24,11 \%$ \\
\hline
\end{tabular}

Fonte: Elaborado pelas autoras. Dados extraídos das Demonstrações Contábeis e Notas Explicativas das empresas. 
Já, em 2016 o segmento de seguros representou na média cerca de 3,03\% das receitas obtidas no segmento de varejo pelas empresas (Magazine Luiza, Via Varejo, Companhia Brasileira de Distribuição e Casas Pernambucanas). Vale destacar que no caso da empresa Via Varejo, o segmento de seguros proporcionou receita equivalente a $7,26 \%$ do segmento de varejo.

Vale destacar que de acordo com as notas explicativas das Lojas Marisa, a empresa possui os seguintes serviços financeiros:

(i) Operaçôes cartão de crédito - por meio do Cartão Marisa e "Co-Branded" Marisa Itaucard e gerenciado pela controlada Club, ofertam aos consumidores da Companhia o crédito para aquisição de produtos, além de seguros, pagamento de contas e empréstimo pessoal.

(ii) Operaçôes crédito pessoal - oferta empréstimo pessoal aos consumidores da Companhia.

Nesse sentido, foram classificadas as operações de crédito pessoal como operaçôes financeiras e as demais receitas foram classificadas como "Receita com Cartōes, Seguros e Produtos Financeiros".

As empresas que não foram possíveis segregar as operaçóes de cartóes, seguros e produtos financeiros foram computadas em conjunto e realizada uma análise global.

Assim, a média das receitas com cartões, seguros e produtos financeiros das empresas Lojas Marisa, Renner e Riachuelo foram de 24,11\% em relação ao segmento de varejo em 2016.

A nota explicativa de 2016 no. 33 da Lojas Renner mencionava que a empresa possuía os seguintes segmentos:

Produtos financeiros: serviços financeiros, com operações de intermediações de serviços financeiros com encargos, empréstimos pessoais, e corretagem de seguros. Aos clientes são também oferecidas assistências e seguros (pessoais, perda e roubo dos cartōes, desemprego e compra garantida). Estes produtos são ofertados em parceria com seguradora e empresa de assistências.

Para o ano de 2015 (Tabela 5), em termos percentuais médios, verificou-se que o segmento financeiro representou na média $12,73 \%$ das receitas obtidas no segmento de varejo pelas empresas (Magazine Luiza, Via Varejo, Casas Pernambucanas e Lojas Marisa). No caso das Casas Pernambucanas, esse percentual atingiu $27,28 \%$ da receita com o varejo. Já, o segmento de seguros foi também de 3,03\% das receitas obtidas no segmento de varejo pelas empresas (Magazine Luiza, Via 
-• Economia Brasileira em Debate

Varejo, Companhia Brasileira de Distribuição e Casas Pernambucanas). Vale destacar que no caso da empresa Via Varejo, o segmento de seguros proporcionou receita equivalente a $6,71 \%$ do segmento de varejo.

Observou-se também em 2015 que média das receitas com cartões, seguros e produtos financeiros das empresas Lojas Marisa, Renner e Riachuelo foram de 22,06\% em relação ao segmento de varejo em 2016.

Tabela 5 Receitas do Varejo, Operações Financeiras e de Seguros (Milhões de R\$ e \%) 2015.

\begin{tabular}{|c|c|c|c|c|c|c|c|}
\hline \multirow[b]{2}{*}{ Empresas } & \multirow{2}{*}{$\begin{array}{c}\text { Receita } \\
\text { bruta do } \\
\text { varejo }\end{array}$} & \multicolumn{2}{|c|}{$\begin{array}{c}\text { Receita } \\
\text { das operações } \\
\text { financeiras }\end{array}$} & \multicolumn{2}{|c|}{$\begin{array}{c}\text { Receita } \\
\text { das operações } \\
\text { de seguros }\end{array}$} & \multicolumn{2}{|c|}{$\begin{array}{c}\text { Receita } \\
\text { com cartões, } \\
\text { seguros e produtos } \\
\text { financeiros }\end{array}$} \\
\hline & & $\begin{array}{c}\text { RS } \\
\text { milhões }\end{array}$ & $\begin{array}{c}\% \text { da } \\
\text { receita } \\
\text { bruta }\end{array}$ & $\begin{array}{c}\text { RS } \\
\text { milhões }\end{array}$ & $\begin{array}{l}\% \% \text { da } \\
\text { receita } \\
\text { bruta }\end{array}$ & $\begin{array}{c}\text { RS } \\
\text { milhões }\end{array}$ & $\begin{array}{c}\% \% \text { da } \\
\text { receita } \\
\text { bruta }\end{array}$ \\
\hline Magazine Luiza & 10.455 & 917 & $8,77 \%$ & 192 & $1,83 \%$ & & \\
\hline Via Varejo & 20.046 & 1.398 & $6,97 \%$ & 1.345 & $6,71 \%$ & & \\
\hline $\begin{array}{l}\text { Companhia } \\
\text { Brasileira de } \\
\text { Distribuição }\end{array}$ & 40.519 & & & 355 & $0,88 \%$ & & \\
\hline $\begin{array}{l}\text { Casas } \\
\text { Pernambucanas }\end{array}$ & 4388 & 1197 & $27,28 \%$ & 119 & $2,71 \%$ & & \\
\hline Lojas Marisa & 2482 & 196 & $7,90 \%$ & & & 486 & $19,58 \%$ \\
\hline Lojas Renner & 5.451 & & & & & 694 & $12,73 \%$ \\
\hline Lojas Riachuelo & 4.073 & & & & & 1380 & $33,88 \%$ \\
\hline Média & 12.488 & 927 & $12,73 \%$ & 503 & $3,03 \%$ & 853 & $22,06 \%$ \\
\hline
\end{tabular}

Fonte: Elaborado pelas autoras. Dados extraídos das Demonstraçôes Contábeis e Notas Explicativas das empresas.

A Tabela 6 apresenta o resultado operacional obtido em cada segmento divulgado da empresa, considerando receitas menos custos e despesas operacionais. Cabe destacar que no caso do Magazine Luiza se refere ao lucro líquido de cada segmento divulgado. 
Tabela 6 Resultado Operacional dos Segmentos de Varejo, Financeiro e de Seguros (Milhões de R\$) - 2016.

\begin{tabular}{|c|c|c|c|c|}
\hline Empresas & $\begin{array}{c}\text { Resultado } \\
\text { operacional } \\
\text { do varejo }\end{array}$ & $\begin{array}{c}\text { Resultado } \\
\text { operacional } \\
\text { das operações } \\
\text { financeiras }\end{array}$ & $\begin{array}{c}\text { Resultado } \\
\text { operacional } \\
\text { das operações } \\
\text { de seguros }\end{array}$ & $\begin{array}{c}\text { Resultado } \\
\text { operacional } \\
\text { das operações } \\
\text { de cartões, seguros } \\
\text { e produtos } \\
\text { financeiros }\end{array}$ \\
\hline Magazine Luiza & 24 & 51 & 12 & \\
\hline Via Varejo & NI & & & \\
\hline $\begin{array}{l}\text { Companhia } \\
\text { Brasileira de } \\
\text { Distribuição }\end{array}$ & NI & & & \\
\hline $\begin{array}{l}\text { Casas } \\
\text { Pernambucanas }\end{array}$ & NI & & & \\
\hline Lojas Marisa & 2 & 54 & & 125 \\
\hline Lojas Renner & 1088 & & & 251 \\
\hline Lojas Riachuelo & $(184)$ & & & 434 \\
\hline
\end{tabular}

Fonte: Elaborado pelas autoras. Nota: NI (Não Informado). Dados extraídos das Demonstrações Contábeis e Notas Explicativas das empresas.

Observa-se pela Tabela 6, que exceto pela Lojas Renner, as demais empresas (Magazine Luiza, Lojas Marisa e Lojas Riachuelo) tiveram resultados operacionais em 2016 mais significativos com produtos financeiros, seguros e cartões do que com a própria atividade principal da empresa que é a comercialização de produtos no varejo. Ou seja, fica evidente a importância dos segmentos de seguros e financeiro para o lucro global da companhia.

A Tabela 7 apresenta o resultado operacional em 2015, e novamente pode-se verificar, que exceto pela Lojas Renner, as demais empresas (Magazine Luiza, Lojas Marisa e Lojas Riachuelo) tiveram resultados operacionais mais significativos nos segmento financeiro, seguros e cartôes do que com a própria atividade principal da empresa que é a comercialização de produtos no varejo. As empresas Magazine Luiza e Lojas Riachuelo, inclusive tiveram prejuízo operacional com a venda de produtos no varejo.

Para a exploração do seu canal de vendas, a rede varejista pode ou não receber um front fee da seguradora, dependendo do potencial que esta entende que a rede pode representar para a comercialização de seus produtos. 
•• Economia Brasileira em Debate

Tabela 7 Resultado Operacional dos Segmentos de Varejo, Financeiro e de Seguros (Milhões de R\$) - 2015.

\begin{tabular}{|c|c|c|c|c|}
\hline Empresas & $\begin{array}{c}\text { Resultado } \\
\text { operacional } \\
\text { do varejo }\end{array}$ & $\begin{array}{c}\text { Resultado } \\
\text { operacional } \\
\text { das operações } \\
\text { financeiras }\end{array}$ & $\begin{array}{c}\text { Resultado } \\
\text { operacional } \\
\text { das operações } \\
\text { de seguros }\end{array}$ & $\begin{array}{c}\text { Resultado } \\
\text { operacional } \\
\text { das operações } \\
\text { de cartões, seguros } \\
\text { e produtos } \\
\text { financeiros }\end{array}$ \\
\hline Magazine Luiza & (66) & 62 & 14 & \\
\hline Via Varejo & NI & & & \\
\hline $\begin{array}{l}\text { Companhia } \\
\text { Brasileira de } \\
\text { Distribuição }\end{array}$ & NI & & & \\
\hline $\begin{array}{l}\text { Casas } \\
\text { Pernambucanas }\end{array}$ & NI & & & \\
\hline Lojas Marisa & 106 & & 56 & 114 \\
\hline Lojas Renner & 1039 & & & 209 \\
\hline Lojas Riachuelo & (64) & & & 337 \\
\hline
\end{tabular}

Fonte: Elaborado pelas autoras.

Nota: NI (Não Informado). Dados extraídos das Demonstraçôes Contábeis e Notas Explicativas das empresas.

Tabela 8 Saldo das Receitas Diferidas Reconhecidas no Passivo (Milhões de R\$) - 2016.

\begin{tabular}{|l|c|c|c|l|}
\hline \multicolumn{1}{|c|}{ Empresa } & $\begin{array}{c}\text { Receita diferida } \\
\text { com operações } \\
\text { financeiras }\end{array}$ & $\begin{array}{c}\text { Receita diferida } \\
\text { com operações } \\
\text { de seguros }\end{array}$ & Outros & Empresa parceira \\
\hline Magazine Luiza & 134 & 413 & 2 & Cardif e Luizaseg \\
\hline Via Varejo & 646 & 982 & 34 & Zurich Minas Brasil \\
\hline $\begin{array}{l}\text { Companhia } \\
\text { Brasileira de } \\
\text { Distribuição }\end{array}$ & & 35 & & \\
\hline
\end{tabular}

Fonte: Elaborado pelas autoras. Dados extraídos das Demonstrações Contábeis e Notas Explicativas das empresas.

A Tabela 8 apresenta os saldos registrados no Balanço Patrimonial decorrentes das antecipações de valores recebidos pelos parceiros comerciais pela exclusividade na prestação de serviços das empresas Magazine Luiza, Via Varejo e Companhia 
Brasileira de Distribuição. Tais valores são reconhecidos como receita diferida e registrados no Passivo da empresa. Vale destacar que tais receitas são reconhecidas na demonstração de resultados à medida que as performances estabelecidas nos respectivos contratos são cumpridas.

\section{CONSIDERAÇÕES FINAIS}

A distribuição de seguros no canal afinidades, tem crescido ao longo do tempo no mercado brasileiro, sendo que esse modelo de negócio acaba fortalecendo o relacionamento do canal varejista com seus clientes, agregando novos produtos à sua marca.

Entretanto, deve-se destacar que a crise econômica vivenciada no país impactou o crescimento do setor de varejo no Brasil, evidenciado pelas estatísticas de vendas e da falta de ânimo dos consumidores diante da incerteza econômica, refletido nas intenções de compra.

Nesse sentido, o presente artigo teve por objetivo realizar uma análise exploratória sobre a importância do segmento de seguros para o setor de varejo, bem como levantar as suas principais características.

Os resultados obtidos a partir da análise das demonstrações contábeis, mais especificamente das notas explicativas das informaçôes por segmento, indicaram que as receitas com os segmentos de seguros e produtos financeiros possuem valores bem representativos em relação às vendas do setor de varejo para os anos de 2015 e 2016.

No caso do resultado operacional, que considera as receitas líquidas de custos e despesas, exceto pela Lojas Renner, as demais empresas (Magazine Luiza, Lojas Marisa e Lojas Riachuelo) tiveram resultados operacionais em 2016 e 2015 mais significativos com produtos financeiros e seguros do que com a própria atividade principal da empresa que é a comercialização de produtos no varejo.

Pelas análises realizadas nas empresas objeto de estudo ficou evidente a importância dos segmentos de produtos financeiros e de seguros para o resultado global da empresa e a rentabilidade do negócio.

\section{REFERÊNCIAS}

BOSCOV, Camila Pereira. O enfoque gerencial na divulgação de informações por segmento. Tese (Doutorado). Faculdade de Economia, Administração e Contabilidade da Universidade de São Paulo, 2009. 
CHAN, Betty Lilian, SILVA, Fabiana Lopes da, MARTINS, Gilberto de Andrade. Fundamentos da Previdência Complementar: da Atuária à Contabilidade. 2. ed. São Paulo: Atlas, 2010.

CHAN, Betty Lilian. Risco de subscrição frente às regras de solvência do mercado segurador brasileiro. São Paulo. 2010. Tese (Doutorado em Ciências Contábeis). Faculdade de Economia, Administração e Contabilidade da Universidade de São Paulo.

COMITÊ DE PRONUNCIAMENTOS CONTÁBEIS. CPC 22 - Informações por segmento. Disponível em: <http://www.cpc.org.br/pdf/CPC\%2022.pdf>. Acesso em: 09/05/2017.

ERNST \& YOUNG; FIPECAFI. Manual de Normas Internacionais de Contabilidade: IFRS versus Normas Brasileiras. São Paulo: Atlas, 2010.

EXAME. Magazine Luiza renova acordo com BNP Paribas Cardif. Matéria publicada em 15/12/2015. Disponível em: http://exame.abril.com.br/negocios/magazine-luiza-renovaacordo-com-bnp-paribas-cardif/. Acesso em: 06/05/2017.

. O que esperar do varejo brasileiro em 2017. Matéria publicada em 12 fevereiro de 2017. Disponível: http://exame.abril.com.br/negocios/o-que-esperar-do-varejo-brasileiro-em-2017/. Acesso em: 09/05/2017.

KOTLER, Philip. Administração de Marketing: análise, planejamento, implementação e controle. São Paulo: Atlas, 1998.

MAPURANGA, Patrícia Vasconcelos Rocha; PONTE, Vera Maria Rodrigues; HOLANDA, Allan Pinheiro. Fatores explicativos da aderência das firmas brasileiras ao disclosure relativo às informações por segmento. Revista Enfoque Contábil, v. 33, n. 1, p. 53-69, 2014.

PINHEIRO, Valéria Aparecida Alves, Camila Pereira. Análise de informações por segmento das empresas premiadas pelo troféu transparência ANEFAC/FIPECAFI/ SERASA 2013. ConTexto, Porto Alegre, v. 15, n. 29, p. 96-112, jan./abr. 2015.

PwC Brasil. O setor de varejo e consumo no Brasil: como enfrentar a crise. Publicado em janeiro de 2016. Disponível em: https://www.pwc.com.br/pt/publicacoes/setoresatividade/assets/produtos-consumo-varejo/2016/pwc-o-setor-varejo-brasil-16.pdf. Acesso em: 09/05/2017.

SBVC (Sociedade Brasileira de Varejo e Consumo). O Papel do Varejo na Economia Brasileira. mar./2017. Disponível em: <http://sbvc.com.br/wp-content/uploads/2017/03/ O-Papel-do-Varejo-na-Economia-dados-2016-Vers\%C3\%A3o-Completa_reduzido. pdf>. Acesso em: 09/05/2017.

SILVA, F. L.; CHAN, B. L. Análise da Demanda e Sinistralidade do Seguro Prestamista. In: Anita Kon; Elizabeth Borelli. (Org.). Aportes ao desenvolvimento da economia brasileira. 1. ed. São Paulo: Blucher, 2015, v. 1, p. 233-253. 
SONHO SEGURO. Zurich pagará $R \$ 270$ milhóes para vender seguros na Via Varejo. Matéria publicada em 21/12/2016. Disponível em: <http://www.sonhoseguro.com. br/2016/12/zurich-pagara-r-270-milhoes-para-vender-seguros-na-via-varejo/>. Acesso em: 05/05/2017.

SOUZA, Edna. Caminhos para o Desenvolvimento. Revista de Seguros. Ano 87, n. 859, out./nov./dez. 2006.

Superintendência de Seguros Privados (SUSEP). Informaçôes sobre o Seguro de Garantia Estendida. Disponível em: <http://www.susep.gov.br/menu/informacoes-ao-publico/ planos-e-produtos/seguros/seguro-de-garantia-estendida-1>. Acesso em: 07/05/2017.

VALOR ECONÔMICO. Seguradora AXA fecha contrato com Pernambucanas de R\$2 bi em prêmios. Matéria publicada em 16.09.2016. Disponível em: <http://www.valor.com. br/financas/4712365/seguradora-axa-fecha-contrato-com-pernambucanas-de-r-2-bi-empremios>. Acesso em: 05/05/2017.

VALOR ECONÔMICO. Lojas Marisa firma contratos com Assurant para venda de seguros. Matéria publicada em 29.03.2017. Disponível em: http://www2.valor.com.br/imprimir/ noticia/4919790/empresas/4919790/lojas-marisa-firma-contratos-com-assurant-paravenda-de-seguros. Acesso em: 05/05/2017. 
